\title{
Oferta de Exportação de Carne de Frango do Brasil, de 1992 a 2007
}

\author{
Márcia Ap. de Paiva Silva ${ }^{1}$ \\ Patrícia Lopes Rosado ${ }^{2}$ \\ Marcelo José Braga ${ }^{3}$ \\ Antônio Carvalho Campos ${ }^{4}$
}

Resumo: $\mathrm{O}$ objetivo deste trabalho foi analisar os determinantes da oferta de exportação de carne de frango no período de 1992 a 2007, quando o setor conquistou maior representatividade nas exportações brasileiras. O modelo teórico fundamentou-se nas relações de oferta e demanda. O modelo econométrico baseouse no Vetor de Correção de Erro (VEC). Para isso, a análise de cointegração pelo procedimento de Johansen foi considerada na análise. Os resultados mostram que o preço doméstico e a renda interna têm significativo impacto nas exportações de carne de frango brasileira, com reflexos negativos no volume embarcado, enquanto o preço externo apresenta impacto significativo e positivo na quantidade exportada.

Palavras-chave: Exportação, carne de frango, Modelos VAR.

Abstract: The objective of this study is to analyze the determinants of chicken meat export supply in the period from 1992 to 2007, when the industry acquired more representativeness in the Brazilian shipments. The theoretical approach is based on the ratios between supply and demand. The econometric model is based on the Johansen's procedure and the Error Correction Vector (VEC). Results show that the Brazilian price and the domestic income have significant impact on the Brazilian chicken meat exports, leading to a negative effect on the shipped volume. The international price presents significant and positive impacts on the amount exported.

Key-words: Exports, chicken meat, VAR models.

Classificação JEL: F10, C32.

1 Mestre em Economia Aplicada pelo Departamento de Economia Rural da UFV. E-mail:marcia_agronegocio@yahoo.com.br

2 Professora-Doutora do Departamento de Economia da Universidade Federal de São João Del Rey. E-mail: patriciarosado@yahoo.com.br

3 Professor-Doutor do Departamento de Economia Rural da UFV.E-mail: mjbraga@ufv.br

4 Professor-Doutor do Departamento de Economia Rural da UFV.E-mail: accampos@ufv.br 


\section{Introdução}

Atualmente, a balança comercial brasileira vem exercendo importante papel no ajuste dos fluxos de capitais internacionais. Apesar das importantes mudanças na pauta de exportação, os produtos agrícolas, embora em menor proporção, apresentam papel fundamental na geração de superávits ou na redução de déficits da balança comercial.

O setor avícola ocupa a terceira posição na cesta de produtos de exportação do agronegócio brasileiro e contribui de modo significativo para o fortalecimento da balança comercial nacional (BARCELLOS, 2006). Segundo Gonçalves e Perez (2006), o alto nível tecnológico alcançado pela avicultura nacional, mais expressivamente a de corte, colocou a atividade em posição privilegiada em relação a outras atividades pecuárias desenvolvidas no Brasil, com nível de produtividade internacional comparado ao dos países mais atualizados no mundo.

A representatividade da atividade avícola para a produção de carnes, tanto em âmbito nacional como internacional, justifica a realização do estudo da oferta de exportação de carne de frango. Costa e Waquil (1999b) afirmaram que a importância dos estudos da exportação de frangos se deve às características da produção, que envolvem uma série de atividades e agentes interdependentes, à importância do setor na balança comercial brasileira e à possibilidade de incorporação de novas tecnologias, proporcionada pelas transações comerciais internacionais.

O objetivo deste trabalho foi analisar os determinantes da oferta de exportação de carne de frango por meio do modelo de Autorregressão Vetorial (VAR) reparametrizado, denominado Vetor de Correção de Erro (VEC), no período de janeiro de 1992 a outubro de 2007.

O trabalho consta de uma parte introdutória, que apresenta a caracterização do setor produtivo e exportador de carne de frango nacional, e de quatro outras seções. Na segunda, há descrição do modelo teórico e analítico; na terceira, são apresentados os resultados; e, na quarta, estão as considerações finais.

\subsection{Caracterização do setor produtor e exportador de carne de frango brasileiro}

A cadeia produtiva de frangos de corte ocupa, atualmente, posição de destaque no agronegócio brasileiro e apresenta grande dinamismo na produção, industrialização, comercialização, progresso tecnológico e mercado externo, além de ser considerada forte geradora de empregos e de renda para a população brasileira. O bom desenvolvimento do setor avícola é decorrente do processo de reestruturação industrial, de mudanças tecnológicas e de melhorias nas técnicas de manejo, nutrição e sanidade das aves, ocorridas nas últimas três 
décadas, aliado ao fato de o País ser um grande produtor de soja e milho, que são os principais componentes da ração de frango de corte (GARCIA, 2004).

Segundo Costa e Waquil (1999a), no período de 1994 a 1997, a avicultura brasileira vivenciou significativas transformações em razão de seu acelerado crescimento, estimulado pela estabilização da renda dos trabalhadores proporcionada pela implementação do Plano Real - e pela menor resposta dos mercados promovida pela estabilização dos preços. A implementação do Plano Real, de fato, resultou em forte consumo brasileiro de frangos, principalmente pela classe com menor poder aquisitivo, que transferiu parte de seu consumo de alimentos energéticos para os protéicos.

O desenvolvimento da cadeia produtiva do setor avícola, bem como o estabelecimento de preços inferiores em relação aos de outras carnes, intensifica o consumo de carne de frango, tanto no mercado interno como no externo (BARCELLOS, 2006; GONÇALVES e PEREZ, 2006). De modo adicional, por apresentar preços competitivos, a produção de carne de frango é o segmento mais dinâmico da cadeia de produção de aves (GONÇALVES e PEREZ, 2006).

Embora o consumo nacional de carne de frango seja bastante acentuado, o Brasil ocupa a quarta posição no consumo mundial, visto que respondeu, em 2007, pelo consumo de 7,12 milhões de toneladas, que corresponde a, aproximadamente, $12 \%$ do consumo mundial. Países como Estados Unidos, China e União Europeia superaram o consumo brasileiro, uma vez que responderam por $23 \%, 18 \%$ e $12,5 \%$, respectivamente, do consumo mundial. No período de 2000 a 2007, o consumo brasileiro de carne de frango cresceu a uma taxa de 5\% ao ano, enquanto o mundial aumentou cerca de $3 \%$ ao ano (ABEF, 2007).

Em consonância com a representatividade do consumo, o Brasil desponta como o terceiro maior produtor mundial de carne de frango. Em 2007, a produção brasileira foi estimada em 9,7 milhões de toneladas, que corresponde a $16 \%$ da produção mundial. Os maiores produtores foram Estados Unidos e China, responsáveis por $27 \%$ e $17 \%$, respectivamente, da produção mundial. De 2000 a 2007, a produção brasileira cresceu a uma taxa de 7,5\% ao ano, o que superou o crescimento da produção mundial, de 3,1\%, e o dos Estados Unidos e da China, que foram de $3 \%$ e $2 \%$ ao ano, respectivamente.

Os principais estados produtores são: Paraná, Santa Catarina e Rio Grande do Sul, que, em 2007, tiveram uma participação de 23\%, 17\% e 15\% na produção nacional, respectivamente. Nas exportações, os estados do Paraná, Santa Catarina e Minas Gerais responderam por 39\%, 21\% e 21\%, respectivamente, do valor exportado, e por $37 \%$, $23 \%$ e $21 \%$, respectivamente, do volume exportado.

As exportações brasileiras do setor avícola iniciaram-se por volta de 1970, quando o setor, ao acompanhar o processo de modernização da agricultura, modificou sua base de produção de uma estrutura de subsistência para uma estrutura empresarial. No período de 1970 a 1980, importantes mudanças ocorreram nos aspectos tecnológicos, produtivos e operacionais na produção 
de aves, o que ocasionou a expansão da produção e o estabelecimento do Brasil como um dos maiores exportadores mundiais de produtos avícolas (COSTA e WAQUIL, 1999b).

Odesempenho brasileiro no comércio internacional é altamente influenciado pelas diversas mutações ocorridas no mercado. De acordo com Bueno (2001), no período de 1984 a 1998, quando foi verificada expansão da participação de alguns países no comércio, como Estados Unidos, China e Hong Kong, registrouse redução de $50 \%$ na parcela brasileira no mercado internacional.

A partir do ano de 2004, o Brasil assumiu a posição - antes ocupada pelos Estados Unidos - de maior exportador. Em 2007, o volume foi de 3,2 milhões de toneladas de carne de frango enviadas ao exterior, o que corresponde a, aproximadamente, $48 \%$ das exportações mundiais do produto (ABEF, 2007). No período de 2000 a 2007, o Brasil apresentou crescimento de $19 \%$ ao ano nas exportações, taxa que se encontra bem acima da dos demais países exportadores, conforme apresentado na Tabela 1.

Os principais destinos das exportações brasileiras foram os países do Oriente Médio, Ásia e União Europeia, que, de janeiro a outubro de 2007, responderam por $30 \%, 25 \%$ e $17 \%$ das exportações de carne de frango, respectivamente.

Tabela 1. Exportações de carne de frango dos principais países (mil toneladas).

\begin{tabular}{ccccccc}
\hline Ano & Brasil & EUA & $\begin{array}{c}\text { União } \\
\text { Europeia }\end{array}$ & Tailândia & China & Mundo \\
\hline 2000 & 907 & 2,231 & 774 & 333 & 464 & 4,856 \\
2001 & 1,265 & 2,520 & 726 & 392 & 489 & 5,527 \\
2002 & 1,625 & 2,180 & 871 & 427 & 438 & 5,702 \\
2003 & 1,960 & 2,232 & 788 & 485 & 388 & 6,023 \\
2004 & 2,470 & 2,170 & 813 & 200 & 241 & 6,055 \\
2005 & 2,846 & 2,360 & 755 & 240 & 331 & 6,791 \\
$2006^{*}$ & 2,713 & 2,454 & 620 & 280 & 350 & 6,470 \\
$2007^{* *}$ & 3,203 & 2,508 & 685 & 280 & 365 & 6,737 \\
\hline Taxa de & $\mathbf{1 8 , 9 \%}$ & $\mathbf{1 , 1 \%}$ & $-\mathbf{2 , 4 \%}$ & $-48, \mathbf{1 \%}$ & $-42,7 \%$ & $4,4 \%$ \\
crescimento & & & & & & \\
\hline
\end{tabular}

* Preliminar; ** Previsão.

Fonte: USDA/Abef, adaptado pelos autores.

No comércio internacional de carnes, as exportações de carne de frango, que ocuparam a primeira posição, corresponderam a cerca de 2,7 milhões toneladas ou $53 \%$ do volume total exportado no setor de carnes. Em termos de receita, a carne de frango ficou na segunda posição entre as demais, já que respondeu por uma receita de US\$3,2 milhões ou, aproximadamente, $40 \%$ do total gerado pelo setor de carnes, estando atrás apenas da carne bovina, que gerou uma receita 
correspondente a $46 \%$ do total gerado pelo setor de carnes (Relatório, 2006). A Tabela 2, a seguir, apresenta as principais informações acerca das exportações do setor de carnes.

Tabela 2. Exportações do setor de carnes - volume (toneladas) e receita (mil US\$).

\begin{tabular}{lcccc}
\hline Especificidade & Volume (t) & Porcentagem & Receita (mil US\$) & Porcentagem \\
\hline Frango & 2.712 .959 & $52,86 \%$ & 3.203 .414 & $36,91 \%$ \\
Bovina & 1.596 .934 & $31,12 \%$ & 3.993 .639 & $46,02 \%$ \\
Suína & 528.195 & $10,29 \%$ & 1.037 .187 & $11,95 \%$ \\
Peru & 156.056 & $3,04 \%$ & 262.821 & $3,03 \%$ \\
Outras Carnes & 138.021 & $2,69 \%$ & 181.887 & $2,10 \%$ \\
\hline Total & $\mathbf{5 . 1 3 2 . 1 6 5}$ & $\mathbf{1 0 0 , 0 0 \%}$ & $\mathbf{8 . 6 7 8 . 9 4 8}$ & $\mathbf{1 0 0 , 0 0 \%}$ \\
\hline
\end{tabular}

Fonte: Abef, 2007. Adaptado pelos autores.

Segundo Gonçalves e Perez (2006), o posicionamento competitivo do Brasil no mercado internacional é fortemente influenciado por políticas protecionistas, adotadas por alguns países, e por questões relacionadas com o controle de sanidade, as quais afetam, diretamente, a qualidade dos alimentos. Alguns problemas, como a expansão da gripe aviária em países da Europa, África e Ásia, são prejudiciais ao setor, por reduzirem a demanda e os preços internacionais.

A continuidade da participação brasileira no mercado internacional é favorecida pela preocupação com excelência sanitária, taxas de câmbio menos sobrevalorizadas, juntamente com competitividade da produção de milho e soja, que garantem a alimentação animal.

\section{Metodologia}

\subsection{Modelo teórico}

As teorias tradicionais do comércio internacional têm como princípio básico as vantagens comparativas. De acordo com essas teorias, o comércio entre os países é decorrente do fato de as nações poderem obter vantagens com a negociação de um produto, ao utilizarem o fator de produção mais abundante e a tecnologia de produção mais eficiente (KRUGMAN e OBSTFELD, 2005).

No entanto, segundo Porter (1993), os pressupostos das teorias do comércio internacional, baseadas em vantagens comparativas, não são condizentes com a realidade. A partir dessa ideia, outros elementos, além da dotação de fatores, passam a ser determinantes no comércio internacional, o que conduz a uma análise sob o enfoque de competitividade.

Sob o aspecto competitivo, o comércio internacional passa a ser influenciado por vários elementos, como tecnologia disponível, preços, custos dos fatores, 
taxas de câmbio, taxas de paridade entre os parceiros comerciais, custos de transporte, estrutura de incentivos, barreiras tarifárias e não tarifárias, entre outros fatores.

Como forma de superar as limitações das teorias tradicionais de comércio, Krugman e Obstfeld (2005) apresentaram um modelo-padrão de uma economia mundial com comércio, pelo qual são desenhadas a curva de oferta relativa mundial a partir das possibilidades de produção e a curva de demanda relativa mundial a partir das preferências. Considerando o modelo-padrão aplicado a dois bens (A e B), a produção, o consumo e o comércio podem ser representados pela Figura 1.

Figura 1. Produção, consumo e comércio no modelo-padrão.

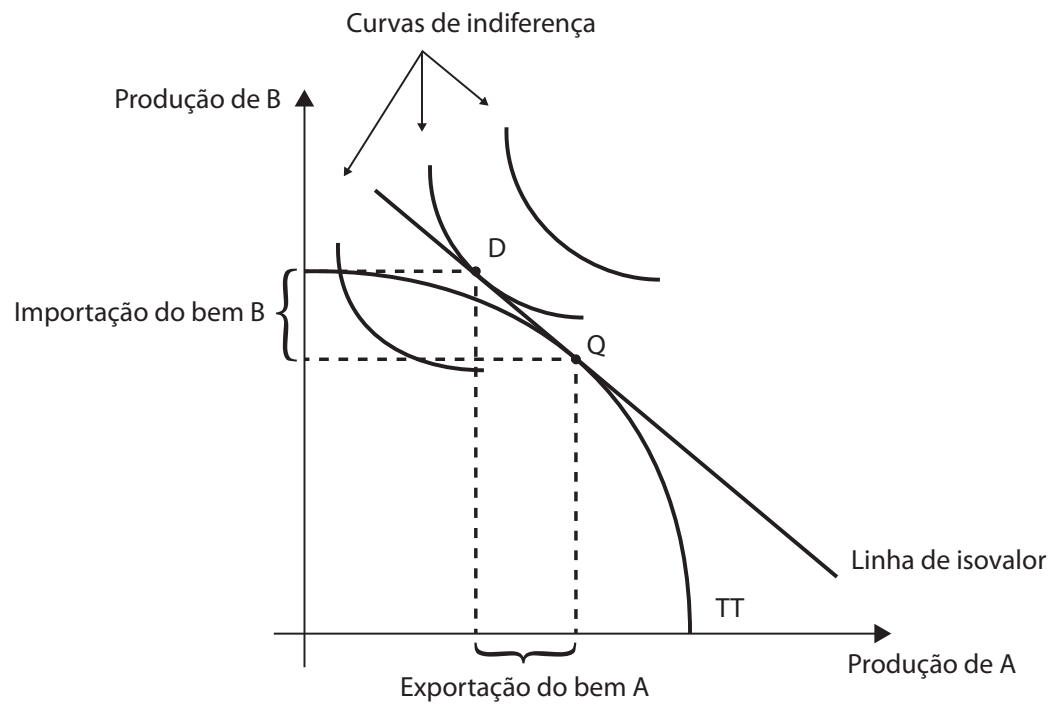

Fonte: Krugman e Obstefeld (2005, p. 72), adaptado pelos autores.

A produção efetiva da economia é determinada pela fronteira de possibilidade de produção, representada pela curva TT. O valor de mercado do produto é representado por uma linha de isovalor, isto é, linha ao longo da qual o valor da produção é constante. A declividade da isovalor é dada pelo negativo do preço relativo do bem $A\left(\mathrm{P}_{\mathrm{A}} / \mathrm{P}_{\mathrm{B}}\right)$.

O consumo efetivo na economia é determinado pelas preferências de um indivíduo representativo ${ }^{5}$, as quais podem ser simbolizadas por uma série de

5 Essa hipótese sustenta-se na ideia de que os indivíduos apresentam as mesmas preferências e respondem pela mesma parcela de todos os recursos, ou de que o governo redistribua a renda a fim de maximizar o bem-estar geral. 
curvas de indiferença que mostram um conjunto de combinações do consumo de A e B, capazes de produzir o mesmo nível de satisfação aos indivíduos.

De acordo com Varian (2003), as preferências simbolizam a escolha, por um indivíduo, de várias cestas de consumo, que contribuem para que o consumidor ordene suas várias opções de consumo. As preferências podem ser representadas, graficamente, pelas curvas de indiferença, que podem representar diversos níveis de satisfação; quanto mais para cima ou mais à direita estiverem localizadas, maior a satisfação do consumidor.

Conforme argumentado por Krugman e Obstfeld (2005), a produção e o consumo devem estar sobre a mesma linha de isovalor, uma vez que o valor do consumo, em uma economia, é igual ao valor de sua produção ${ }^{6}$.

Assim, o nível de produção é determinado pelo ponto de tangência entre a curva de possibilidade de produção (TT) e a linha de isovalor, graficamente representado pelo ponto $Q$. De forma similar, o nível de consumo é determinado pelo ponto de tangência da linha de isovalor com a mais alta curva de indiferença (representado pelo ponto D), a fim de aumentar o bem-estar do consumidor.

Considerando que o nível de produção e o consumo sejam predeterminados, observa-se que a produção do bem A excede o seu consumo (eixo horizontal), o que resulta na exportação desse bem. No entanto, o consumo do produto B excede a sua produção, o que determina a importação desse bem (eixo vertical).

Krugman e Obstfeld (2005) enfatizaram que o comércio surge em determinado mercado quando os preços, medidos em uma mesma moeda, forem diferentes na ausência de comércio. Para estabelecer o preço mundial e a quantidade comercializada, devem-se determinar a curva de demanda de importação de determinado bem e a curva de oferta de exportação do país exportador do mesmo bem, as quais são derivadas das curvas de oferta e demanda domésticas.

A demanda de importação do país importador refere-se ao excesso do que os consumidores desse país demandam sobre os que os produtores locais ofertam. Entretanto, a oferta de exportação do país exportador é definida pelo excesso do que os produtores desse país ofertam sobre o que os consumidores locais demandam.

6 A igualdade entre valor da produção e do consumo baseia-se na ideia de que um país não pode gastar mais do que recebe, embora a quantidade de cada bem que esse país consome e produz seja diferente. No caso dos bens A e B, a igualdade entre produção e consumo pode ser representada pela seguinte equação:

$P_{A} Q_{A}+P_{B} Q_{B}=P_{A} D_{A}+P_{B} D_{B}$

em que:

$P_{A}$ e $P_{B}$ : preços dos bens $A$ e $B$, respectivamente;

$Q_{A}$ e $Q_{B}$ : quantidades produzidas dos bens $\mathrm{A}$ e $\mathrm{B}$, respectivamente; e

$D_{A}$ e $D_{B}$ : consumo dos bens $A$ e $B$, respectivamente. 
Segundo Varian (2003), a curva de oferta indica a quantidade de mercadoria que os produtores estão dispostos a vender, a determinado preço, considerando constantes quaisquer outros fatores que possam afetar a quantidade ofertada. A curva de oferta apresenta inclinação positiva, uma vez que os preços e a quantidade ofertada apresentam relação direta.

Vasconcellos (2006) acrescentou que a oferta é afetada por outras variáveis, além do preço, e representa a função de oferta por meio da expressão:

$$
Q_{i}^{s}=f\left(P_{i}, P_{f p}, P_{n}, T, M\right)
$$

em que $Q_{i}^{s}$ é quantidade ofertada do bem i; $P_{i}$, preço do bem i; $P_{f p}$, preço dos fatores e dos insumos de produção (matéria-prima, mão de obra etc.); $P_{n}$, preços de outros bens substitutos na produção; $T$, tecnologia; e $M$, metas e objetivos do empresário.

A curva de demanda, por sua vez, informa a quantidade que os consumidores desejam comprar, à medida que varia o preço unitário, mantidos os demais fatores constantes (VARIAN, 2003). A curva de demanda apresenta relação inversa com os preços, ou seja, um aumento nos preços de determinado bem implica redução na quantidade demandada desse bem. Além do preço, a demanda é afetada ainda por outras variáveis: renda, preço de bens relacionados e gostos do consumidor:

$$
Q_{i}^{D}=f\left(P_{i}, P_{s}, P_{C}, R, G\right)
$$

em que $Q_{i}^{D}$ é quantidade procurada (demandada) do bem i; $P_{i}$, preço do bem i; $P_{s}$, preço dos bens substitutos ou concorrentes; $P_{C}$, preço dos bens complementares; $R$, renda do consumidor; e $G$, gostos, hábitos e preferências do consumidor.

Considerando as condições de oferta e demanda doméstica, a derivação da curva de oferta exportação de um país é representada pela Figura 2. Se o preço estiver ao nível de $\mathrm{P} 1$, os produtores domésticos irão ofertar $\mathrm{O}^{1}$, enquanto os consumidores domésticos irão consumir $\mathrm{D}^{1}$; portanto, a quantidade disponível para exportação será dada pela diferença entre $\mathrm{O}^{1}$ e $\mathrm{D}^{1}\left(\mathrm{O}^{1}\right.$ - $\left.\mathrm{D}^{1}\right)$. Se o preço do bem aumentar de $\mathrm{P} 1$ para $\mathrm{P} 2$, os produtores elevarão a sua quantidade ofertada para $\mathrm{O}^{2}$, ao passo que os consumidores reduzirão a quantidade demandada de $\mathrm{D}^{2}$, o que fará com que a quantidade disponível para a exportação aumente, passando a ser representada pela diferença entre $\mathrm{O}^{2}$ e $\mathrm{D}^{2}\left(\mathrm{O}^{2}-\mathrm{D}^{2}\right)$. A oferta de bens disponíveis para a exportação aumentará à medida que o preço elevar; portanto, a curva de oferta de exportação será positivamente inclinada. Ao nível de preço $P^{*}$, oferta e demanda serão iguais; logo, haverá ausência de comércio. 
Figura 2. Curva de oferta de exportação.

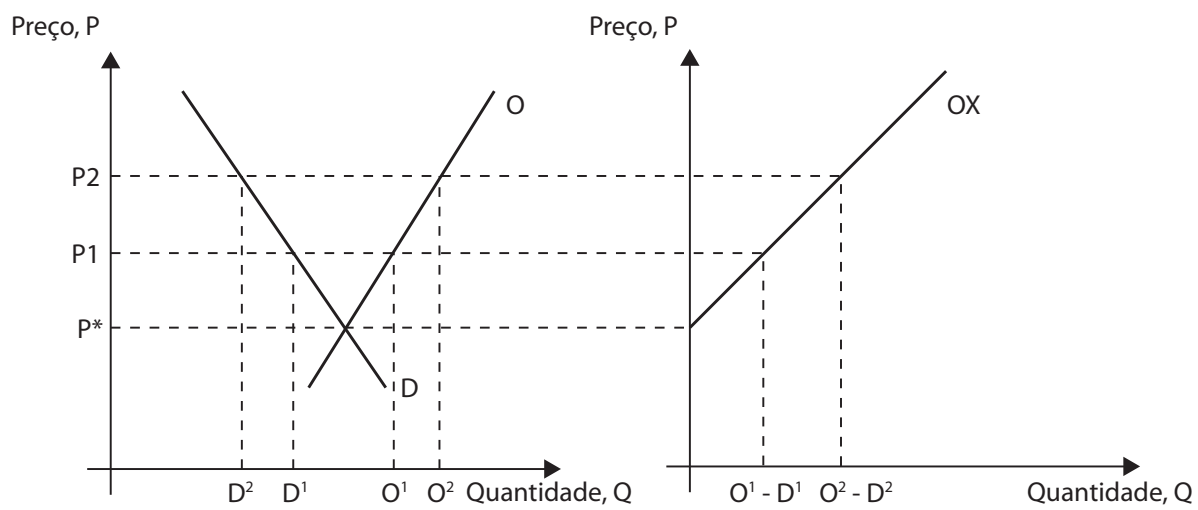

Fonte: Krugman e Obstfeld (2005, p. 141), adaptado pelos autores.

O equilíbrio mundial ocorrerá quando a demanda de importação do país importador se igualar à oferta de exportação do país exportador. A partir dessa igualdade, serão determinados preço e quantidade de equilíbrio comercializada no mercado internacional.

O preço internacional, expresso em diferentes moedas, tornar-se-á comparável por intermédio da taxa de câmbio, definida pelo preço da moeda de um país expresso pela moeda de outro país (KRUGMAN e OBSTFELD, 2005). No entanto, a variação da taxa de câmbio poderá ser determinante na definição das exportações, uma vez que a depreciação da moeda de um país, em relação à estrangeira ${ }^{7}$, tornará suas exportações mais baratas e suas importações mais caras, e uma apreciação de sua moeda tornará suas exportações mais caras e suas importações mais baratas.

Em termos práticos, a taxa de câmbio pode ser determinada por:

$$
E=\frac{P}{P *}
$$

em que $P$ é o preço de um bem no mercado doméstico, em moeda nacional; e $P^{*}$, preço do mesmo bem no mercado externo, em dólares. O comportamento dos preços interno e externo de um produto pode ser determinante para a variação da taxa de câmbio.

7 Entende-se por depreciação da moeda de um país, em relação à moeda estrangeira, a elevação dos preços da moeda estrangeira em moeda doméstica. No entanto, a apreciação da moeda de um país, em relação à estrangeira, seria uma redução no preço da moeda estrangeira em moeda doméstica. 


\subsection{Modelo analítico}

\subsubsection{Modelo econômico}

Em trabalhos realizados são identificadas diversas variáveis que afetam a oferta de exportação de produtos agropecuários. Barros et al. (2002) e Alves e Bacchi (2004) consideraram que os fatores determinantes para as exportações eram o preço interno e externo dos bens em consideração, a renda interna e a taxa de câmbio.

De acordo com os trabalhos revisados, o modelo econômico, que sustenta a análise dos determinantes da oferta de exportação de carne de frango, é dado por:

$$
Q X_{t}=f\left(P D_{t}, P E_{t}, Y_{t}, T C_{t}\right)
$$

em que $Q X_{t}$ é quantidade exportada de frango, no período $\mathrm{t} ; P D_{t}$, preço doméstico de carne de frango, no período $\mathrm{t}$; $P E_{t}$, preço externo de carne de frango, no período $\mathrm{t}$; $Y_{t}$, renda interna no período t; e $T C_{t}$, taxa de câmbio, no período t.

As variáveis foram logaritmizadas para se obterem, diretamente, as elasticidades, que correspondem aos próprios coeficientes estimados. Segundo Alves e Bacchi (2004), a transformação dos dados em logaritmo reduz os problemas associados à variância não constante dos erros, quando existirem.

Por um lado, espera-se que os coeficientes estimados do preço externo e da taxa de câmbio sejam positivos e que exprimam uma relação direta com a quantidade exportada de carne de frango. Isso ocorre porque um aumento no preço externo deverá levar a aumento na quantidade ofertada de carne de frango, e um aumento na taxa de câmbio - uma depreciação do real - deverá corresponder a um incentivo ao aumento das exportações.

Por outro, espera-se que os sinais dos coeficientes de preço doméstico e da renda interna ${ }^{8}$ sejam negativos e que exprimam uma relação inversa com a oferta de exportação de carne de frango. Isso se justifica, pois um aumento na renda interna conduziria a aumento no consumo de produtos internos, levando a uma queda na disponibilidade de produtos para exportação. Em relação ao preço doméstico, essa relação negativa poderia ser decorrente do fato de o equilíbrio no mercado interno sinalizar escassez ou não do produto, isto é, preço elevado sinaliza escassez e, portanto, menor exportação.

\footnotetext{
8 A relação inversa oferta de exportação e renda interna é apresentada nos trabalhos de
} Barros et al. (2002) e Alves e Bacchi (2004). 


\subsubsection{Procedimentos metodológicos}

Em toda a análise que envolve dados de séries temporais, deve-se, primeiramente, verificar a ordem de integração das séries e, a partir dessa informação, identificar se a série possui raiz unitária ou se é estacionária em nível.

Entre os diversos testes empregados para avaliar a estacionaridade de uma série temporal, tem-se o Dickey-Fuller Aumentado (ADF), que é utilizado para testar a presença de raiz unitária, que constitui uma situação de não estacionaridade (5).

$$
\Delta Y_{t}=\alpha+\beta T+\delta Y_{t-1}+\sum_{i=1}^{n} \Delta Y_{t-i}+\varepsilon_{t}
$$

em que $\Delta$ é o operador de primeira diferença $\left(\Delta Y_{t}=Y_{t}-Y_{t-1}\right) ; \alpha$, termo de intercepto; $T$, tendência; $\delta(=\rho-1)$, coeficiente de teste da presença ou ausência de raiz unitária; $\Delta Y_{t-1}$, própria variável dependente, diferenciada e defasada, cujo objetivo é eliminar a possibilidade de presença de autocorrelação dos resíduos; e $\varepsilon_{t}$, estrutura de erros, que se pressupõe ter média zero, variância constante e ausência de autocorrelação.

Conforme se pode verificar, na expressão (5) estão presentes o termo de intercepto e a variável tendência. No entanto, ao utilizar o teste de ADF é necessário testar, também, variações na referida expressão, ou seja, testar a presença de raiz unitária por meio da estimação de outras duas expressões: em uma delas se exclui apenas a variável tendência e, na outra, além dessa variável, o termo de intercepto.

Com base na autorregressão (5), testam-se as hipóteses nula $\left(H_{0}: \delta=0\right) \mathrm{e}$ alternativa $\left(H_{1}: \delta=1\right)$. Se a hipótese nula não for rejeitada $\left(|\tau|_{\text {calculado }}<|\tau|_{\text {abelado }}\right)$, a série da variável $Y_{t}$ será não estacionária em nível, existindo, portanto, o problema de raiz unitária (LÜTKEPOHL e KRÄTZIG, 2004). Com base no teste de ADF, pode-se, portanto, identificar a ordem de integração de determinada série, ou seja, qual é a ordem de diferenciação que torna a série estacionária (exemplo: I(1), indica que a série é estacionária na primeira diferença).

Para definir o número de defasagens empregadas na realização dos testes de ADF, neste trabalho foi utilizado o critério de SBC (SCHWARZ Bayesian Criterion), com o intuito de minimizar a possível presença de autocorrelação nos resíduos.

Para identificar o possível relacionamento de longo prazo entre as variáveis, utilizou-se o teste de cointegração, elaborado por Johansen e Jeselius (1990), já que o mesmo possibilita identificar o maior conjunto de variáveis que compartilham o mesmo comportamento de longo prazo, visto que a análise é conduzida por uma estrutura multivariada.

O procedimento de Johansen (1991), para testar a cointegração, baseia-se na versão reparametrizada de um modelo $\operatorname{VAR}(\mathrm{p})$, representado da seguinte forma: 


$$
\Delta X_{t}=\Gamma_{1} \Delta X_{t-1}+\cdots+\Gamma_{p-1} \Delta X_{t-p+1}+\prod_{1} X_{t-1}+\xi_{t}
$$

em que $X_{t}$ é um vetor $(k \times 1)$ de variáveis estocásticas; $\xi_{t}$, erros idêntica e independentemente distribuídos, ou seja, que seguem a distribuição normal; e $\Pi=\alpha \beta^{\prime}$, em que $\alpha$ e $\beta^{\prime}$ são matrizes $(k \times r)$, sendo $r$ o posto da matriz $\Pi$, que é igual ao número de vetores linearmente independentes ou cointegrados, e p, o número de defasagens das variáveis.

A determinação de que $r$ é o posto da matriz $\Pi$ permite inferir que esta tenha $r$ autovalores diferentes de zero, e três situações podem ocorrer: (i) se $r=k$, então $y_{t}$ será estacionário e a questão de cointegração não será pertinente; (ii) se $r=0$, então $\Delta y_{t}$ será estacionário e não haverá relação de cointegração entre as variáveis; e (iii) se $0<r<k$, haverá $r$ relações de cointegração que fornecerão $r$ vetores de cointegração. Nesse último caso, há ainda matrizes $\alpha$ e $\beta$ de dimensão $k x r$, tais que $\prod=\alpha \beta^{\prime}$ e o vetor $\beta^{\prime} y_{t}$ é estacionário, havendo, portanto, $r$ vetores de cointegração (as $r$ colunas de $\beta$ ) que definem as relações de equilíbrio de longo prazo entre as variáveis; $\alpha$, matriz de coeficientes de ajustamento para o equilíbrio de longo prazo; e $\Gamma_{i}$, matrizes de coeficientes que definem a dinâmica de curto prazo.

Portanto, para testar a cointegração das séries temporais utilizadas neste trabalho, foram utilizados os testes traço $\left(\lambda_{\text {traco }}\right)$ e de máximo autovalor $\left(\lambda_{\text {max }}\right)$, propostos por Johansen e Juselius (1990). Segundo esses autores, as hipóteses do teste traço são montadas para verificar a existência do número máximo de $(r)$ vetores cointegrados, ou seja, $H_{0}: r_{0} \leq r$ e $H_{1}: r_{0}>r$.

Entretanto, a hipótese nula do teste de máximo autovalor é formulada para verificar o número exato de vetores de cointegração, contra a hipótese alternativa de existência de $r+1$ vetores: $H_{0}: r_{0}=r$ e $H_{1}: r+1$.

Os testes traço e máximo autovalor são denotados, respectivamente, por $\lambda_{\text {traco }}=-T \sum_{i=n_{0}+1}^{p} \operatorname{In}\left(1-\lambda_{i}\right), \operatorname{com} r=0,1,2, \ldots, p-1$, e $\lambda_{\max }=-\operatorname{TIn}\left(1-\lambda_{r 0}+1\right)$, em que T é o número de observações e $\lambda_{i}$, autovetores estimados. Tanto na estatística traço quanto na de máximo autovalor, para os valores que forem maiores que os níveis críticos estabelecidos por Johansen e Juselius, rejeita-se $H_{0}\left(H_{0}\right.$ : ausência de cointegração).

Admitindo que todas as variáveis explicativas contidas no modelo sejam I(1) e que também sejam cointegradas, é possível estimar a equação (7) e, dessa forma, resolver o problema da perda das informações no longo prazo.

$$
L \hat{Q} X_{t}=\hat{c}+\hat{\beta}_{1} L P D_{t}+\hat{\beta}_{2} L P E_{t}+\hat{\beta}_{3} L Y_{t}+\hat{\beta}_{4} L T C_{t}+u_{t-1}
$$

em que $L Q X_{t}$ é o logaritmo da quantidade exportada; $L P D_{t}$, logaritmo do preço doméstico; $L P E_{t}$, logaritmo do preço externo; $L Y_{t}$, logaritmo da renda nacional; $L T C_{t}$, logaritmo da taxa de câmbio; e $u_{t}=$ termo de erro aleatório com as propriedades usuais. 
Segundo Lütkepohl (2004), os métodos de Autorregressão Vetorial (VAR) e de Autorregressão Vetorial reparametrizada (VEC) possibilitam a decomposição da variância dos erros de previsão $k$ períodos à frente, o que permite determinar a evolução do comportamento dinâmico apresentado pelas variáveis do modelo econômico, ao longo do tempo. Assim, torna-se possível a separação da variância dos erros de previsão para cada variável em componentes que podem ser atribuídos por ela própria e pelas demais variáveis endógenas isoladamente, apresentando, em termos percentuais, o efeito que um choque não antecipado sobre determinada variável teria sobre ela própria e sobre as demais variáveis pertencentes ao sistema (MARGARIDO et al., 2002).

De acordo com Margarido et al. (2002), ao analisar o efeito de choques individuais sobre a dinâmica do sistema, torna-se necessário diagonalizar a matriz de variância e covariância dos resíduos para evitar que choques sobre determinada variável contaminem todo o sistema, impedindo a análise de seu efeito individual sobre o comportamento da variável de interesse. O procedimento utilizado neste estudo para diagonalizar essa matriz foi o da decomposição de Cholesky, ${ }^{9} \mathrm{com}$ a seguinte ordenação: LTC, LY, LPE, LPD e LQX.

\subsection{Fonte de dados e descrição das variáveis}

Os dados de quantidade exportada (em kg) e de valor das exportações de carne de frango ${ }^{10}$, utilizado no cálculo do preço externo (US\$ $/ \mathrm{kg}$ ), foram obtidos da Secretaria de Comércio Exterior do Ministério da Indústria e Comércio (Mdic/Secex), e os preços domésticos (em R\$/kg), da Fundação Getúlio Vargas (FGV/Agroanalysis). Os preços foram deflacionados pelo Índice Geral de Preços - Disponibilidade Interna (IGP-DI), da Fundação Getúlio Vargas - Conjuntura Econômica (FGV/Conjuntura Econômica). A taxa de câmbio real utilizada foi o índice calculado pelo Ipea, denominado Taxa de Câmbio Efetiva Real (IPA-OG - exportações), calculado a partir da taxa de câmbio nominal (R\$/US\$). A renda interna foi representada utilizando-se como proxy o Produto Interno Bruto Nacional (PIB, em US\$), obtido do Banco Central do Brasil. Os dados utilizados têm frequência mensal e foram transformados em logaritmos, para melhor ajustamento do modelo. Na operacionalização do modelo foi empregado o software econométrico Eviews 6.0.

9 Para mais detalhes sobre o processo de diagonalização da matriz de variânciacovariância, ver Lutkepohl (2004).

10 No presente estudo, os dados de carne de frango englobam carne e miúdos de frango congelado, fresco ou refrigerado. De acordo com a classificação da Nomenclatura Comum do Mercosul (NCM), o setor de carne de frango compõe a seção I, que corresponde a animais vivos e produtos do reino animal. O capítulo 2, da NCM, trata das posições referentes a carnes, miudezas e comestíveis, e o grupo de carnes de frango ocupa a sétima posição. 


\section{Resultados e discussão}

Inicialmente, foram realizados os testes de raiz unitária de Dickey Fuller Aumentado (ADF), para analisar a estacionaridade das séries quantidade exportada (LQX), preço doméstico (LPD), preço externo (LPE), renda nacional (LY) e taxa de câmbio (LTC), todas logaritmizadas. Os resultados são apresentados na Tabela 3.

Os resultados apontam que, considerando as séries em nível, não se pode rejeitar a presença de raiz unitária a $1 \%$ e $5 \%$ de probabilidade para todas as séries, o que indica que todas elas são não estacionárias. Em primeira diferença, os testes indicam que, em nível de significância de $5 \%$, todas as séries são estacionárias. Portanto, constata-se que todas elas são estacionárias em primeira diferença e, por possuírem a mesma ordem de integração, podem ser cointegradas.

Tabela 3. Teste de raiz unitária Dickey-Fuller Aumentado para as séries quantidade exportada, preço doméstico, preço exportação, renda doméstica e taxa de câmbio, logaritmizadas, de janeiro de 1992 a outubro de 2007.

\begin{tabular}{|c|c|c|c|c|c|c|}
\hline \multirow{3}{*}{$\begin{array}{l}\text { Série } \\
\text { LQX }\end{array}$} & \multirow{3}{*}{$\begin{array}{c}\text { Equação do Teste } \\
\text { Constante e tendência }\end{array}$} & \multirow{3}{*}{$\begin{array}{c}\begin{array}{c}\text { Número de } \\
\text { Defasagens }(\mathrm{p}-1)\end{array} \\
3\end{array}$} & \multirow{2}{*}{\multicolumn{2}{|c|}{$\begin{array}{l}\text { Estatística } \\
\text { de Teste }\end{array}$}} & \multicolumn{2}{|c|}{ Valor Crítico } \\
\hline & & & & & \multirow{2}{*}{$\begin{array}{c}5 \% \\
-3,43\end{array}$} & \multirow{2}{*}{$\begin{array}{c}1 \% \\
-4,00\end{array}$} \\
\hline & & & $\tau_{\tau}$ & $-3,15$ & & \\
\hline$\Delta \mathrm{LQX}$ & Sem const. e sem tend. & 2 & $\tau$ & $-12,65$ & $-1,94$ & $-2,57$ \\
\hline LPD & Constante & 2 & $\tau_{\mu}$ & $-1,88$ & $-2,87$ & $-3,46$ \\
\hline$\Delta \mathrm{LPD}$ & Sem const. e sem tend. & 1 & $\tau$ & $-11,68$ & $-1,94$ & $-2,57$ \\
\hline LPE & Sem const. e sem tend. & 3 & $\tau$ & $-1,57$ & $-1,94$ & $-2,57$ \\
\hline$\triangle \mathrm{LPE}$ & Sem const. e sem tend & 2 & $\tau$ & $-5,45$ & $-1,94$ & $-2,57$ \\
\hline LY & Constante & 12 & $\tau_{\mu}$ & $-1,68$ & $-2,87$ & $-3,46$ \\
\hline$\Delta \mathrm{LY}$ & Sem const. e sem tend & 11 & $\tau$ & $-1,95$ & $-1,94$ & $-2,57$ \\
\hline LTC & Constante & 1 & $\tau_{\mu}$ & $-1,96$ & $-2,87$ & $-3,46$ \\
\hline$\Delta \mathrm{LTC}$ & Sem const. e sem tend. & 0 & $\tau$ & $-10,07$ & $-1,94$ & $-2,57$ \\
\hline
\end{tabular}

Fonte: Dados de pesquisa.

$\mathrm{Na}$ obtenção dos resultados da análise de cointeração, para as séries integradas de mesma ordem, utilizou-se o procedimento de Johansen, a partir da especificação de um modelo VAR. Na identificação do número de defasagens do modelo VAR foi empregado o critério de Schwarz, que, segundo Enders (1995), é o mais parcimonioso, pois identificou a existência de apenas uma defasagem, conforme apresentado na Tabela 4 . 
Tabela 4. Definição do número de defasagens do modelo VAR, a partir do critério de Schwarz

\begin{tabular}{cccc}
\hline Defasagens & Akaike & Schwarz & Hannan-Quin \\
\hline 0 & $-3,37$ & $-3,28$ & $-3,34$ \\
1 & $-14,33$ & $-13,79^{*}$ & $-14,11$ \\
2 & $-14,56$ & $-13,58$ & $-14,16^{*}$ \\
3 & $-14,62$ & $-13,19$ & $-14,04$ \\
4 & $-14,68^{*}$ & $-12,80$ & $-13,92$ \\
\hline
\end{tabular}

*Valor mínimo de cada critério, utilizado na escolha do número de defasagens.

Fonte: Dados de pesquisa.

O teste de cointegração de Johansen, considerando os testes do traço e do máximo autovalor, é apresentado na Tabela 5. Segundo o teste de traço, a hipótese de que o posto da matriz de cointegração é nulo é rejeitada, ao passo que não se rejeita a hipótese $r \geq 1$, em nível de significância de $5 \%$. Da mesma forma, de acordo com o teste do máximo autovalor, a hipótese de que o posto da matriz de cointegração é nulo é rejeitada, em nível de significância de 5\%; nesse nível de significância, não se rejeita a hipótese alternativa $r=1$. Constatase, assim, a existência de um vetor de cointegração, ou seja, uma relação de equilíbrio no longo prazo.

Tabela 5. Teste do traço e do máximo autovalor para cointegração ${ }^{11}$ entre as variáveis LQx, LPD, LPE, LY e LTC.

\begin{tabular}{cccccccc}
\hline & \multicolumn{2}{c}{ Teste do Traço } & \multicolumn{3}{c}{ Teste do Máximo Autovalor } \\
\hline $\mathrm{H}_{0}$ & $\mathrm{H}_{1}$ & $\begin{array}{c}\text { Valor } \\
\text { Observado }\end{array}$ & $\begin{array}{c}\text { Valor } \\
\text { Crítico }\end{array}$ & $\mathrm{H}_{0}$ & $\mathrm{H}_{1}$ & $\begin{array}{c}\text { Valor } \\
\text { Observado }\end{array}$ & $\begin{array}{c}\text { Valor } \\
\text { Crítico }\end{array}$ \\
\hline $\mathrm{r}=0$ & $\mathrm{r} \geq 1$ & $88,45^{*}$ & 76,97 & $\mathrm{r}=0$ & $\mathrm{r}=1$ & $36,46^{*}$ & 34,80 \\
$\mathrm{r} \leq 1$ & $\mathrm{r} \geq 2$ & 51,99 & 54,07 & $\mathrm{r} \leq 1$ & $\mathrm{r}=2$ & 26,15 & 28,58 \\
$\mathrm{r} \leq 2$ & $\mathrm{r} \geq 3$ & 25,83 & 35,19 & $\mathrm{r} \leq 2$ & $\mathrm{r}=3$ & 17,56 & 22,29 \\
$\mathrm{r} \leq 3$ & $\mathrm{r} \geq 4$ & 8,26 & 20,26 & $\mathrm{r} \leq 3$ & $\mathrm{r}=4$ & 5,95 & 15,89 \\
$\mathrm{r} \leq 4$ & $\mathrm{r} \geq 5$ & 2,31 & 9,16 & $\mathrm{r} \leq 4$ & $\mathrm{r}=5$ & 2,31 & 9,16 \\
\hline
\end{tabular}

$\mathrm{H}_{0}$ e $\mathrm{H}_{1}$ representam as hipóteses nula e alternativa, respectivamente; *significa não rejeição de $\mathrm{H}_{\mathrm{o}}$, a $5 \%$. Fonte: Dados de pesquisa.

11 Foi escolhido o modelo com constante e sem tendência, o qual não apresenta tendência determinística (modelo 2) pelo fato de a tendência não se apresentar estatisticamente diferente de zero, a 10\% de significância, e o termo constante significativo, o que levou à inclusão deste no vetor de correção de erro. 
$\mathrm{Na}$ análise do padrão de interdependência dos fatores determinantes da exportação de carne de frango utilizaram-se as estimativas dos parâmetros do modelo Vetor de Correção de Erros (VEC), como definido na equação 4. Assim, com o intuito de analisar as relações de longo prazo entre os diferentes fatores determinantes das exportações de carne de frango, foram estimados os parâmetros do modelo VEC e procedeu-se à estimação da relação de cointegração, normalizada em relação ao logaritmo da quantidade exportada de frango, de modo que o valor dessa variável fosse igual a 1. A Tabela 6 apresenta o vetor de cointegração entre as variáveis LQX, LPD, LPE, LY e LTC, no período de janeiro de 1992 a outubro de 2007.

Tabela 6. Vetor de cointegração normalizado pelo método de Johansen janeiro de 1992 a outubro de 2007.

\begin{tabular}{cccccc}
\hline LQX & Intercepto & LPD & LPE & LY & LTC \\
\hline 1,00 & $-188,52^{*}$ & $11,30^{*}$ & $-4,06^{*}$ & $5,65^{*}$ & $4,79^{* * *}$ \\
& {$[-3,72]$} & {$[5,84]$} & {$[-2,79]$} & {$[3,50]$} & {$[1,89]$} \\
\hline
\end{tabular}

Nota: Os termos entre colchetes referem-se às estatísticas do teste " $\mathrm{t}$ " de Student.

* Significativo a $1 \%$ de probabilidade; ** Significativo a $5 \%$ de probabilidade; ** Significativo a $10 \%$ de probabilidade.

Fonte: Dados de pesquisa.

Considerando os resultados da Tabela 6, a relação de equilíbrio no longo prazo é dada pela equação (8), a seguir, que equivale à função de oferta de exportação estimada.

$$
\hat{\log Q X_{t}}=188,52-11,30 L P D_{t}+4,06 L P E_{t}-5,65 L Y_{t}-4,79 \beta_{4} L T C_{t}
$$

De acordo com essa equação, apenas o sinal do parâmetro da taxa de câmbio $\left(\beta_{4}\right)$ não se apresentou condizente com a teoria e não foi estatisticamente significativo, aos níveis de $1 \%$ e $5 \%$, segundo o teste " $\mathrm{t}$ " de Student. Todos os demais parâmetros foram significativos a $1 \%$ e $5 \%$.

O coeficiente do logaritmo do preço doméstico (LPD) indica que, mantidas as demais variáveis constantes, um acréscimo (decréscimo) de $1 \%$ no preço doméstico deveria reduzir (aumentar) a quantidade exportada em 11,30\%.

A elasticidade-preço direta da oferta de exportação de carne de frango, medida pelo coeficiente do logaritmo do preço externo (LPE), evidencia que, ceteris paribus, um acréscimo (decréscimo) de $1 \%$ no preço externo da carne de frango deveria induzir a aumento (redução) de $4,06 \%$ na quantidade exportada. Portanto, verifica-se que a oferta de exportação é elástica.

Em relação ao coeficiente do logaritmo da renda nacional (LY), verifica-se que, mantido tudo o mais constante, um acréscimo (decréscimo) de $1 \%$ na renda interna deveria provocar redução (aumento) de 5,65\% na quantidade 
exportada de carne de frango. Isso ocorre porque, conforme argumentaram Souza e Burnquist (2007), Satolo e Bacchi (2006), Souza Neto et al. (2006) e Alves e Bacchi (2004), um aumento na renda interna induziria a um aumento no consumo interno, o que reduziria a disponibilidade de produto direcionado à exportação.

Embora o coeficiente do logaritmo da taxa de câmbio não tenha sido estatisticamente significativo $1 \%$ e $5 \%$ e contasse com sinal contrário ao esperado, prosseguiu-se a sua análise. O coeficiente de LTC indica que, ceteris paribus, um aumento na taxa de câmbio de $1 \%$ provocaria queda de $4,79 \%$ na quantidade exportada.

Como justificativa para a baixa significância da taxa de câmbio e seu sinal contrário ao esperado, Sousa e Osaki (2006) afirmaram que, uma vez que o maior volume de exportações brasileiras é destinado ao Oriente Médio e à União Europeia, em que a taxa de câmbio é dada em reais por euro, a taxa de câmbio em reais por dólar pode não ter impacto significativo sobre as exportações. Além disso, outros fatores, como a gripe aviária, são prejudiciais à produção e à exportação brasileiras e influenciam o volume destinado ao mercado externo. Gonçalves et al. (2007) afirmaram que a resposta das exportações a mudanças na taxa de câmbio exige tempo e não pode ser representada num mesmo período.

Tendo em vista que a taxa de câmbio pode ser representada pela razão entre o preço interno e externo de carne de frango e que o preço doméstico teve constante queda a partir de 1995, considera-se plausível a relação inversa entre a taxa de câmbio e a quantidade exportada de carne de frango. Isso ocorre porque as exportações apresentaram comportamento crescente no período de 1992 a 2007; em contrapartida, a taxa de câmbio, por efeito da queda dos preços domésticos, mostrou comportamento descendente.

O coeficiente de ajustamento de curto prazo $(\alpha)$ pode ainda ser obtido pela análise de cointegração. Esses coeficientes mostram a velocidade de ajustamento de curto prazo das variáveis em direção ao equilíbrio de longo prazo. Em suma, diante de um desequilíbrio transitório (de curto prazo), um elevado valor para $\alpha$ indica que a velocidade de ajuste será rápida em direção ao equilíbrio de longo prazo. No entanto, um valor pequeno de $\alpha$ mostra que a velocidade será baixa e, consequentemente, a transição de uma situação de desequilíbrio de curto prazo para uma situação de equilíbrio no longo prazo tenderá a ser corrigida lentamente. Na Tabela 7 são apresentados os resultados do ajustamento de curto prazo para cada uma das variáveis quantidade exportada (LQX), preço doméstico (LPD), preço externo (LPE), renda interna (LY) e taxa de câmbio (LTC), todas logaritmizadas.

No curto prazo, o coeficiente da quantidade exportada de carne de frango (LQX) é de 0,0341. Desse modo, constata-se que desequilíbrios transitórios nessa variável são corrigidos a uma velocidade de 3,41\%, que se apresenta uma velocidade baixa, mas relativamente mais rápida entre todas as demais variáveis. 
Tabela 7. Coeficientes de ajustamento $(\alpha)$ do modelo de correção de erros irrestrito, janeiro de 1992 a outubro de 2007

\begin{tabular}{ccccc}
\hline LQX & LPD & LPE & LY & LTC \\
\hline$-0,03$ & $-0,00$ & 0,00 & 0,00 & $-0,00$ \\
{$[-2,23]$} & {$[-1,54]$} & {$[3,47]$} & {$[0,56]$} & {$[-4,31]$} \\
\hline
\end{tabular}

Fonte: Dados de pesquisa.

A metodologia VAR permite, ainda, avaliar o poder explanatório de cada variável sobre as demais por meio da decomposição da variância do erro de previsão. Entretanto, como o modelo VAR é sensível à ordenação das variáveis parte e das menos endógenas para as mais endógenas, optou-se por ordenar as variáveis da seguinte forma: LTC, LY, LPE, LPD e LQX. As Tabelas 8 a 12, apresentam a referida decomposição para o logaritmo da quantidade exportada (LQX), do preço doméstico (LPD), do preço externo (LPE), da renda interna (LY) e da taxa de câmbio (LTC). São apresentadas, ainda, as estimativas dos desvios padrão e a proporção dos erros atribuída a cada variável explicativa do modelo.

Na Tabela 8, nota-se que, no período de 24 meses, o preço doméstico explica $0,08 \%$ a $12,60 \%$ da variância do erro de previsão da quantidade exportada (LQX), enquanto a renda nacional (LNY) explica 1,30\% a 1,61\% da variância do erro de previsão de LQX, após o quarto mês. O preço das exportações e a taxa de câmbio têm menor poder explicativo sobre o erro de previsão da quantidade exportada do referido produto.

Tabela 8. Decomposição histórica do erro de previsão de LQX.

\begin{tabular}{ccccccc}
\hline Período & $\begin{array}{c}\text { Desvio- } \\
\text { padrão }\end{array}$ & LQX & LPD & LPE & LY & LTC \\
\hline 1 & 0,23 & 97,29 & 0,07 & 1,23 & 1,29 & 0,09 \\
4 & 0,44 & 97,71 & 0,89 & 0,77 & 0,54 & 0,07 \\
8 & 0,60 & 95,33 & 3,71 & 0,45 & 0,44 & 0,04 \\
12 & 0,73 & 92,23 & 6,68 & 0,31 & 0,72 & 0,03 \\
16 & 0,83 & 89,49 & 9,16 & 0,25 & 1,06 & 0,02 \\
20 & 0,93 & 87,28 & 11,10 & 0,21 & 1,36 & 0,02 \\
24 & 1,02 & 85,55 & 12,60 & 0,20 & 1,61 & 0,01 \\
\hline
\end{tabular}

Fonte: Dados de pesquisa.

Com relação à decomposição da variância dos erros do preço doméstico (LPD), verifica-se que, no mês, 1, 95,37\% referem-se à influência do seu próprio preço; $2,74 \%$, da taxa de câmbio (LTC); $1,27 \%$, da renda (LY); e 0,61\%, do preço externo (LPE). Esses resultados mostram que, na formação do LPD, as variáveis LTC e LY são as mais relevantes no primeiro mês. No entanto, sua importância relativa decresce 
ao longo do tempo, enquanto LY, LTC, LPE e LQX têm importância na composição do LPD, chegando ao mês 24 com uma participação de, aproximadamente, $80,83 \%$ na sua formação (Tabela 9).

Tabela 9. Decomposição histórica do erro de previsão de LPD.

\begin{tabular}{ccccccc}
\hline Período & $\begin{array}{c}\text { Desvio- } \\
\text { padrão }\end{array}$ & LQX & LPD & LPE & LY & LTC \\
\hline 1 & 0,04 & 0,00 & 95,36 & 0,61 & 1,27 & 2,73 \\
4 & 0,07 & 0,16 & 92,86 & 1,12 & 2,65 & 3,19 \\
8 & 0,10 & 0,59 & 89,43 & 1,77 & 4,53 & 3,66 \\
12 & 0,12 & 1,03 & 86,47 & 2,32 & 6,15 & 4,00 \\
16 & 0,14 & 1,42 & 84,11 & 2,76 & 7,44 & 4,25 \\
20 & 0,15 & 1,73 & 82,26 & 3,10 & 8,45 & 4,43 \\
24 & 0,16 & 1,98 & 80,83 & 3,36 & 9,24 & 4,57 \\
\hline
\end{tabular}

Fonte: Dados de pesquisa.

No que se refere à variável LPE, a maior parcela da decomposição do erro de previsão deve-se ao próprio comportamento da variável. Decorridos 24 meses da incidência do choque não antecipado sobre o LPE, cerca de 60,41\% da decomposição do seu erro de previsão deve-se à sua própria influência, que é a mais relevante ao longo de todo o período; 24,71\%, ao LPD; 8,64\%, ao LY; 6,17, ao LQX; e 0,06\%, ao LTC. Esses resultados mostram que, na formação do LPE, além do seu próprio preço, a variável LPD é a mais relevante. Isso ocorre, conforme sugeriram Alves e Bachi (2004), em decorrência da interação dos mercados nacional e internacional (Tabela 10).

Tabela 10. Decomposição histórica do erro de previsão de LPE.

\begin{tabular}{ccccccc}
\hline Período & $\begin{array}{c}\text { Desvio- } \\
\text { padrão }\end{array}$ & LQX & LPD & LPE & LY & LTC \\
\hline 1 & 0,04 & 0,00 & 0,00 & 99,96 & 0,02 & 0,01 \\
4 & 0,07 & 0,78 & 3,15 & 95,11 & 0,93 & 0,00 \\
8 & 0,11 & 2,49 & 9,99 & 84,19 & 3,30 & 0,01 \\
12 & 0,14 & 3,92 & 15,72 & 74,96 & 5,35 & 0,03 \\
16 & 0,16 & 4,94 & 19,81 & 68,35 & 6,84 & 0,04 \\
20 & 0,18 & 5,66 & 22,67 & 63,71 & 7,89 & 0,05 \\
24 & 0,21 & 6,17 & 24,71 & 60,40 & 8,64 & 0,06 \\
\hline
\end{tabular}

Fonte: Dados de pesquisa. 
Nas Tabelas 11 e 12 são apresentados os resultados da decomposição da variância para renda nacional (LY) e para taxa de câmbio (LTC). Para a renda nacional, observa-se que a taxa de câmbio (LTC) explica, a partir do quarto mês, 4,6\% a 3,93\% da sua variância do erro de previsão; em relação aos choques nas demais variáveis, a renda desenvolve-se de maneira relativamente independente. No tocante à taxa de câmbio, observa-se que o preço doméstico (LPD) e a renda (LY) tiveram maior impacto na variância do erro de previsão, que foi de $4,39 \%$ a $26,13 \%$ e $1,69 \%$ a $10,05 \%$, respectivamente, a partir do quarto mês; a quantidade exportada e o preço externo, por sua vez, explicaram 1,09\% a $6,52 \%$ e $0,48 \%$ a $2,86 \%$ da variância do erro de previsão da taxa de câmbio, a partir do quarto mês.

Tabela 11. Decomposição histórica do erro de previsão de LY.

\begin{tabular}{ccccccc}
\hline Período & $\begin{array}{c}\text { Desvio- } \\
\text { padrão }\end{array}$ & LQX & LPD & LPE & LY & LTC \\
\hline 1 & 0,05 & 0,00 & 0,00 & 0,00 & 95,39 & 4,60 \\
4 & 0,11 & 0,01 & 0,07 & 0,00 & 95,48 & 4,40 \\
8 & 0,16 & 0,06 & 0,25 & 0,02 & 95,42 & 4,23 \\
12 & 0,20 & 0,10 & 0,40 & 0,04 & 95,33 & 4,11 \\
16 & 0,23 & 0,13 & 0,52 & 0,05 & 95,24 & 4,03 \\
20 & 0,26 & 0,15 & 0,62 & 0,06 & 95,17 & 3,97 \\
24 & 0,28 & 0,17 & 0,69 & 0,07 & 95,12 & 3,93 \\
\hline
\end{tabular}

Fonte: Dados de pesquisa.

Tabela 12. Decomposição histórica do erro de previsão de LTC

\begin{tabular}{ccccccc}
\hline Período & $\begin{array}{c}\text { Desvio- } \\
\text { padrão }\end{array}$ & LQX & LPD & LPE & LY & LTC \\
\hline 1 & 0,03 & 0,00 & 0,00 & 0,00 & 0,00 & 100,00 \\
4 & 0,07 & 1,09 & 4,39 & 0,48 & 1,69 & 92,33 \\
8 & 0,10 & 3,10 & 12,43 & 1,36 & 4,78 & 78,31 \\
12 & 0,14 & 4,54 & 18,22 & 1,99 & 7,01 & 68,21 \\
16 & 0,17 & 5,48 & 21,97 & 2,40 & 8,45 & 61,67 \\
20 & 0,19 & 6,10 & 24,44 & 2,67 & 9,40 & 57,37 \\
24 & 0,22 & 6,52 & 26,12 & 2,86 & 10,05 & 54,43 \\
\hline
\end{tabular}

Fonte: Dados de pesquisa. 


\section{Conclusões}

O objetivo deste trabalho foi analisar os determinantes das exportações de carne de frango no período de 1992 a 2007, por meio do modelo de Autorregressão Vetorial (VAR). Como as variáveis foram integradas em primeira diferença, utilizou-se um VAR restrito ou reparametrizado, denominado de Vetor de Correção de Erro (VEC).

De maneira isolada, as variáveis que refletem diretamente as condições do mercado interno - preço doméstico e renda interna - foram de grande importância na determinação das exportações brasileiras de carne de frango. O preço externo também apresentou significativa influência na quantidade exportada de carne de frango, o que corrobora o preceito de que esse fator é um sinalizador da absorção de carne de frango no mercado externo e evidencia que a oferta de exportação de carne de frango é elástica ao preço externo.

A taxa de câmbio não apresentou impacto estatisticamente significativo, porque, conforme indicaram alguns autores, existem outros fatores, como a taxa de câmbio em reais por euro, e fatores relativos à sanidade animal, como incidência de gripe aviária, que podem responder pela variação das exportações de carne de frango. Ademais, não se pode desconsiderar a forte defasagem temporal entre a variação cambial e seu impacto nas exportações brasileiras.

Em suma, neste trabalho, constata-se que, embora os fatores apresentados sejam importantes determinantes das exportações de carne de frango, no período de 1992 a 2007, há outros que podem influenciar o comércio internacional. Apesar de apresentarem excelência na produtividade, tecnologia e recursos produtivos, os produtores brasileiros devem preocupar-se, sobremaneira, com elementos de ordem de segurança alimentar, uma vez que o risco de gripe aviária é pertinente.

Essa constatação reforça a necessidade de qualificação dos produtores e exportadores nacionais, com vistas ao atendimento das exigências cada vez mais restritivas dos países importadores, além do desenvolvimento de programas de certificações e indicadores que garantam os padrões de qualidade da carne de frango brasileira.

Em trabalhos posteriores, sugere-se a utilização da taxa de câmbio em reais por euro para verificar seus impactos na oferta de exportação de carne de frango e compará-los com os resultados discutidos neste trabalho. Recomendase, ainda, a realização de futuras análises que identifiquem outras variáveis determinantes, bem como o estudo dos efeitos de políticas protecionistas e de barreiras não-tarifárias sobre as exportações de carne de frango. 


\section{Referências Bibliográficas}

ASSOCIAÇÃO BRASILEIRA dos Exportadores de Frango do Brasil ABEF. Estatísticas. Disponível em: <http://www.abef.com.br/Estatisticas/ MercadoMundial/MercadoMundial.asp> . Acesso em: 15 dez 2007.

ASSOCIAÇÃO BRASILEIRA dos Exportadores de Frango do Brasil - ABEF. Relatório Anual. São Paulo, SP. 2006. Disponível em: <http://www.abef.com.br/ portal/_clientes/abef/cat/Relatorio_2006_9062.pdf>. Acesso em: 8 jan. 2008.

ALVES, L. R. A.; BACCHI, M. R. P. Oferta de exportação de açúcar do Brasil. Revista de Economia e Sociologia Rural, Brasília, DF, v. 42, n. 1, jan-mar/2004.

BANCO CENTRAL DO BRASIL - BACEN. Estatísticas. Disponível em < https:// www3.bcb.gov.br/sgspub/localizarseries/localizarSeries.do? method = prepararT elaLocalizarSeries>. Acesso em 15 dez. 2007.

BARCELLOS, O. Uma reflexão do comércio internacional dos setores de carne de frango e de soja do Brasil e Mercosul. Perspectiva Econômica, v.2, n. 2, p. 15 - 36, jul./dez. 2006.

BARROS, G. S, C.; BACCHI, M. R. P.; BURNQUIST, H. L. Estimação de equações de oferta de exportação de produtos agropecuários para o Brasil (1992/2000). Brasília: IPEA, 2002. n. 865, (Texto para Discussão).

BUENO, Y. M. Determinantes das estratégias de marketing no setor exportador de frangos. 2001.94 p. Dissertação (Mestrado em Economia Aplicada) - Universidade Federal de Viçosa, Viçosa-MG, 2001.

COSTA, T. V. M. Integração regional e seus efeitos sobre as exportações brasileiras de carne avícola. 1999. 128 p. Dissertação (Mestrado em Economia Aplicada) Universidade Federal do Rio Grande do Sul, Porto Alegre, 1999a.

COSTA, T. V. M.; WAQUIL, P.D. comércio intra-mercosul de frangos: intensidade, orientação regional e vantagens comparativas. Teoria e Evidência Econômica, v. 7, n. 12, p. 9-35, maio 1999b.

ENDERS, W. Applied econometric time series. New York, John Wiley \& Sons, Inc., 1995. 433p.

GARCIA, L. A. F. Economias de escala na produção de frangos de corte no Brasil. 2004. 114 p. Tese (Doutorado em Economia Aplicada) - Escola Superior de Agricultura "Luiz de Queiroz", Universidade de São Paulo, São Paulo, 2004.

GONÇALVES, J. S.; PEREZ, L. H. Exportações brasileiras da cadeia de produção de aves no período 2000-2005: origem, destino e agregação de valor. Informações Econômicas, v.36, n.7, p 32-47, jul. 2006. 
GONÇALVES, V. C.; FREITAS, C. A.; NICOLA, D. S.; PAZ, M. V. O desempenho das exportações brasileiras de carnes e grãos no período 1990-2004. In: CONGRESSO BRASILEIRO DE ECONOMIA E SOCIOLOGIA RURAL, 45., 2007, Londrina. Artigo Completo... Londrina, PR: SOBER, 2007. Cd-Rom

HAMILTON, J. D. Time series analysis. Princeton, New Jersey: Princeton University, 1994.

Instituto de Pesquisa Econômica Aplicada - IPEA. Estatísticas. Disponível em <www.ipedata.gov.br>. Acesso em: 15 dez. 2007.

JOHANSEN, S. Statistical analysis of cointegration vectors. Journal of Economic Dynamics \& Control, v. 12, p. 231-254, 1988.

JOHANSEN, S.; Estimation and hypothesis testing of cointegration vectors in gaussian vector autorregressive models. Econometrica, v. 59, p. 1551-1580, 1991.

JOHANSEN, S., JUSELIUS, K. Maximum likelihood estimation and inference on cointegration - with application to the demand for money. Oxford Bulletin on Economics and Statistics, v. 52, n. 1, p. 169-210, 1990.

KRUGMAM, P. R.; OBSTEFELD, M. Economia internacional: teoria e política. São Paulo: Makron Books, 2005. 807 p.

LÜTKEPOHL, H.; KRÄTZIG, M. Applied time series econometrics. New York: Cambridge University Press, 2004. 323 p.

MARGARIDO, M. A.; Fernandes, J. M.; TUROLLA, F. A. Análise da formação dos preços no mercado internacional de soja: o caso do Brasil. Agricultura em São Paulo, v. 47, n.2, p.71-85, 2002.

MDIC/SECEX. Ministério do Desenvolvimento, Indústria e Comércio Exterior. Alice web: dados das Exportações brasileiras por período. Disponível em: < http:// www.aliceweb.desenvolvimento.gov.br>. Acesso em: 15 dez. 2007.

PORTER, M. E. Vantagem competitiva das nações. Rio de Janeiro: Campus, 1993. 897 p.

SOUSA, D. P.; OSAKI, M. Gripe aviária: primeiros impactos nas exportações brasileiras. In: CONGRESSO BRASILEIRO DE ECONOMIA E SOCIOLOGIA RURAL, 44., 2006, Fortaleza. Anais... Fortaleza, CE: SOBER, 2006. Cd-Rom

VARIAN, H. R. Microeconomia: princípios básicos. Uma abordagem moderna. Rio de Janeiro: Elsevier, 2003. 778 p.

VASCONCELLOS, M. A. S. Economia: micro e macro. 4. ed. São Paulo: Atlas, 2006. $441 \mathrm{p}$. 